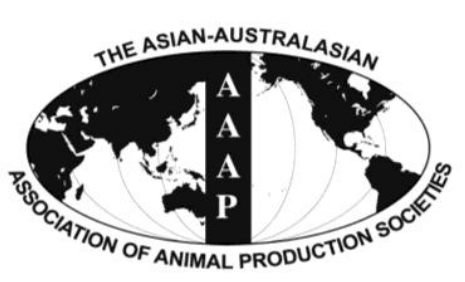

Open Access

Asian Australas. J. Anim. Sci.

Vol. 27, No. 12 : 1749-1754 December 2014

http://dx.doi.org/10.5713/ajas.2014.14294

www.ajas.info

pISSN 1011-2367 elSSN 1976-5517

\title{
Evaluation of Dietary Multiple Enzyme Preparation (Natuzyme) in Laying Hens
}

\author{
K. W. Lee, Y. I. Choi, E. J. Moon, S. T. Oh, H. H. Lee, C. W. Kang, and B. K. An* \\ Department of Animal Science and Technology, Konkuk University, Seoul 143-701, Korea
}

\begin{abstract}
The current experiment was designed to evaluate the efficacy of adding the multi-enzyme mixture (Natuzyme) into layers' diets with different levels of energy and available phosphorus in relation to laying performance, egg qualities, blood cholesterol level, microflora and intestinal viscosity. Two hundred and fifty 43 -wk-old Hy-Line commercial layers were divided into five groups with five replicates per group (10 birds per replicate) and fed one of five experimental diets. A corn and soybean meal-based control diet was formulated and used as a control diet. Two experimental control diets were formulated to reduce energy and crude protein contents $(\mathrm{rE})$ or energy, crude protein and phosphorus contents (rEP). In addition, Natuzyme was added into either rE (rE-Natu500) or rEP (rEPNatu500) diet to reach a concentration of $500 \mathrm{mg}$ per $\mathrm{kg}$ of diet. The experiment lasted 8 weeks. There were no significant differences in feed intake, egg production, egg weight, egg qualities such as eggshell color or Haugh unit, total cholesterol, relative organ weights and cecal microflora profiles between any dietary treatments. Natu500 supplementation into the $\mathrm{rE}$ diet, but not rEP diet significantly increased egg mass and eggshell qualities such as strength and thickness, but it decreased cecal ammonia concentration and intestinal viscosity in laying hens. In conclusion, the present study shows that adding multiple enzyme preparation could improve performance of laying hens fed energy and protein restricted diets. (Key Words: Multiple Enzyme Preparation, Egg Qualities, Performance, Intestinal Viscosity)
\end{abstract}

\section{INTRODUCTION}

Alternative strategies to antibiotics have been mainstream of topics for researches in animal science to sustain the animal production (Lillehoj and Lee, 2012). The most widely accepted alternatives include probiotics, prebiotics, exogenous enzymes, and phytogenics including plant extracts in poultry. In addition, the novel concept which employs the natural enhancement of host immunity by alternatives has been gained much interest as a coccidiosis control measure in broiler chickens (Lee et al., 2011; Lee et al., 2013).

Exogenous enzyme has long been used in poultry industry to alleviate the anti-nutritional factors and improve the utilization of dietary energy and protein, thus leading to enhanced poultry performance (Ravindran, 2013). To reflect

\footnotetext{
* Corresponding Author: Byoung-Ki An. Tel: +82-2-450-3294, Fax: +82-2-452-9946, E-mail: abk7227@hanmail.net

Submitted Apr. 19, 2014; Revised May 28, 2014; Accepted Jun. 26, 2014
}

the widespread use of the exogenous enzyme, the global enzyme market has been rapidly increased which is estimated to worth more than US\$ 550 million dollars (Adeola and Cowieson, 2011). It is well accepted that exogenous enzymes upon ingestion act on anti-nutritional factors present in plant-based feedstuffs such as phytic acid or non-starch polysaccharides, of which components are known to be biologically unavailable to chickens. Due to the structural complexity in feedstuffs, it has been pointed out that the multiple enzyme preparations with the substrate-specific activities be regarded as the next generation of technology (Ravindran, 2013). Indeed, the additive effect of multiple enzyme preparation with phytase, carbohydrases and proteases has been reported in broiler chickens when fed onto the nutritionally deficient diet. It is however understood that the responses to exogenous enzyme in poultry with respect to performance of chickens has been variable and also depends on many factors such as age or quality or type of diet used (Bedford and Schulze, 1998; Adeola and Cowieson, 2011; Ravindran, 2013). It is 
thus warranted to accumulate the relevant performance data on the efficacy of multiple enzyme-based preparations which is of practical use and relevant to poultry industry. In this regard, the present study was conducted to evaluate the commercially available multiple enzyme preparation (Natuzyme) which contains cellulase, xylanase, $\beta$-glucanase, amylase, protease, pectinase, phytase, and lipase, in laying hens. Until now, there is lack of information on the effect of the enzyme preparation in laying hens while a couple of performance trials with Natuzyme have been reported with broiler chickens. In this study, we evaluated various parameters such as laying performance, egg qualities, gut physiology, cholesterol concentration, cecal microflora and intestinal viscosity, of which factors are considered importance in laying hens.

\section{MATERIALS AND METHODS}

\section{Enzyme preparation}

A multiple enzyme preparation, Natuzyme (Bioproton
Pty Ltd., Sunnybank, Australia) is a powder form composed of xylanase $(10,000,000$ unit $/ \mathrm{kg})$, cellulase $(5,000,000$ unit $/ \mathrm{kg}), \quad \beta$-glucanase $(1,000,000$ unit $/ \mathrm{kg})$, pectinase $(140,000 \mathrm{unit} / \mathrm{kg})$ from Trichoderma reesei and Trichoderma longibrachiatum. It also contains protease $(6,000,000$ unit $/ \mathrm{kg})$ and phytase $(500,000$ unit $/ \mathrm{kg})$ from Aspergillus niger, and $\alpha$-amylase $(1,800,000 \mathrm{unit} / \mathrm{kg})$ from bacillus subtilis.

\section{Birds and experimental design}

Two hundred and fifty 43-wk-old Hy-Line Variety Brown laying hens were randomly allotted to 5 dietary treatments and each treatment has 5 replicates, 10 hens per replicate. A corn and soybean meal-based diet (Table 1) was formulated to meet or exceed the nutrients requirement recommended by National Research Council (NRC, 1994) and used as the control diet. Two experimental control diets were formulated to reduce energy and crude protein contents (rE) or energy, crude protein and phosphorus contents (rEP). Natuzyme was added into either rE (rE-

Table 1. The ingredients and chemical compositions of experimental diets ${ }^{1}$

\begin{tabular}{|c|c|c|c|c|c|}
\hline Items & Control & $\mathrm{rE}$ & rE/Natu500 & $\mathrm{rEP}$ & rEP/Natu500 \\
\hline \multicolumn{6}{|l|}{ Ingredients (\%) } \\
\hline Yellow corn & 57.80 & 55.28 & 55.23 & 55.12 & 55.07 \\
\hline Soybean meal & 22.91 & 20.64 & 20.64 & 20.58 & 20.58 \\
\hline Corn gluten meal & 4.73 & 3.50 & 3.50 & 3.46 & 3.46 \\
\hline Wheat bran & 1.54 & 8.11 & 8.11 & 8.52 & 8.52 \\
\hline Tallow & 1.50 & 1.00 & 1.00 & 1.00 & 1.00 \\
\hline Vitamin mixture $^{2}$ & 0.21 & 0.21 & 0.21 & 0.21 & 0.21 \\
\hline Mineral mixture ${ }^{3}$ & 0.20 & 0.20 & 0.20 & 0.20 & 0.20 \\
\hline DL-methionine (99\%) & 0.07 & 0.07 & 0.07 & 0.07 & 0.07 \\
\hline Dicalcium phosphate & 1.42 & 1.27 & 1.27 & 0.83 & 0.83 \\
\hline Limestone & 9.19 & 9.29 & 9.29 & 9.58 & 9.58 \\
\hline Choline- $\mathrm{Cl}(50 \%)$ & 0.13 & 0.13 & 0.13 & 0.13 & 0.13 \\
\hline Salt & 0.30 & 0.30 & 0.30 & 0.30 & 0.30 \\
\hline Natuzyme & - & - & 0.05 & - & 0.05 \\
\hline Total & 100 & 100 & 100 & 100 & 100 \\
\hline \multicolumn{6}{|c|}{ Calculated composition (\%) } \\
\hline Crude protein & 18.00 & 17.00 & 17.00 & 17.00 & 17.00 \\
\hline Ether extract & 4.03 & 3.66 & 3.66 & 3.67 & 3.67 \\
\hline Crude fiber & 2.97 & 3.34 & 3.34 & 3.37 & 3.37 \\
\hline Crude ash & 13.28 & 13.32 & 13.32 & 13.18 & 13.18 \\
\hline Calcium & 3.90 & 3.90 & 3.90 & 3.90 & 3.90 \\
\hline Available phosphorus & 0.35 & 0.35 & 0.35 & 0.27 & 0.27 \\
\hline Lysine & 0.86 & 0.82 & 0.82 & 0.82 & 0.82 \\
\hline Cys+Met & 0.72 & 0.68 & 0.68 & 0.68 & 0.68 \\
\hline TMEn (kcal/kg) & 2,810 & 2,720 & 2,720 & 2,720 & 2,720 \\
\hline
\end{tabular}

TMEn, nitrogen-corrected true metabolizable energy.

${ }^{1} \mathrm{rE}$, diet with the reduced level of energy and protein; Natu500, 0.05\% Natuzyme; rEP, diet with the reduced level of energy, protein and available phosphorus.

${ }^{2}$ Vitamin mixture provided the following nutrients per kg of diet: vitamin A, 40,000 IU; vitamin $\mathrm{D}_{3}, 8,000 \mathrm{IU}$; vitamin E, $11 \mathrm{IU}$; vitamin $\mathrm{K}_{3}, 4.00 \mathrm{mg}$; vitamin $\mathrm{B}_{1}, 4.00 \mathrm{mg}$; vitamin $\mathrm{B}_{2}, 12.00 \mathrm{mg}$; vitamin $\mathrm{B}_{6}, 6.00 \mathrm{mg}$; vitamin $\mathrm{B}_{12}, 0.02 \mathrm{mg}$; pantothenic acid, $20.00 \mathrm{mg}$; folic acid, $2.00 \mathrm{mg}$; nicotinic acid $60.00 \mathrm{mg}$.

${ }^{3}$ Mineral mixture provided the following nutrients per kg of diet: Fe, $60.00 \mathrm{mg} ; \mathrm{Zn}, 50.00 \mathrm{mg}$; Mn, $40.00 \mathrm{mg}$; Cu, $10.00 \mathrm{mg} ; \mathrm{Co}, 0.30 \mathrm{mg} ; \mathrm{Se}, 0.20 \mathrm{mg}$. 
Natu500) or rEP (rEP-Natu500) diet to reach a concentration of $500 \mathrm{mg}$ per $\mathrm{kg}$ of diet as the manufacturer recommended. The diet and water were provided on an $a d-$ libitum basis. The experiment lasted 8 weeks. All experimental protocols were approved by the Animal Care Committee of KonKuk University.

\section{Sampling and measurements}

Feed consumption per replicate was recorded weekly and used to calculate daily feed intake per hen. Eggs were daily collected twice a day (morning and afternoon), weighted and used to calculate the egg mass (egg production in percentxegg weight in grams). Eggshell thickness without shell membrane was determined by micrometer (Digimatic micrometer, Series 293-330, Mitutoyo, Japan). Breaking strength of uncracked eggs was measured with an eggshell strength tester (FHK, Fujihira Ltd., Tokyo, Japan). Eggshell color, albumen height and yolk color were measured by using egg multi tester made by TSS (Technical Services and Supplies Ltd, York, England). Haugh unit was calculated as described elsewhere (Han et al., 1999).

At the end of experiment, blood samples were obtained individually from ten birds per treatment ( 2 per replicate) after cervical dislocation. Immediately after blood sampling, organs (liver and spleen) and intestine (Ileum and ceca) were excised. Liver and spleen were weighed and expressed as relative weight in grams per $100 \mathrm{~g}$ of body weight. Intestinal contents were sampled from Meckel's diverticulum and the ileocecal junction per hen and kept on ice until the measurement of viscosity on the same day of the sampling. Cecal contents were aseptically sampled and kept on ice until used for gut microbiota analysis on the same day of the sampling. Sera were obtained by gentle centrifugation for $15 \mathrm{~min}$ and stored at $-20^{\circ} \mathrm{C}$ for later use.

Total cholesterol concentration in serum samples was spectrophotometrically measured using the commercially available kit (Cholesterol E kit, Asan Phamaceutical Co., Seoul, Korea). The enzyme activities for glutamicoxaloacetic transaminase (GOT) or glutamic-pyruvic transaminase (GPT) were assayed using a commercially available GOP-GPT assay kit (Asan Pharmaceutical, Hwaseoung, Korea) as the manufacturer recommended. For the microbial analysis, approximately one gram of the cecal contents was homogenized with phosphate buffer saline using a homogenizer (AM 77 model, Nissei, Anjo-shi, Japan) and subjected to serial dilution until $10^{-7}$. The diluted samples were plated on the Nutrient agar (Difco, BD Science, Franklin Lakes, NJ, USA), MRS agar (Difco, BD Science, USA), and MacConkey agar (Difco, BD Science, USA) to count bacterial total microbes, presumptive lactic acid bacteria, and presumptive coliform bacteria. These plates were incubated at $37^{\circ} \mathrm{C}$ for $24 \mathrm{~h}$. The results were expressed as $\log$ base 10 colony-forming units (cfu) per gram of cecal contents. The cecal ammonia concentration and viscosity of intestinal contents were measured according to a protocol of Lee et al. (2010). In brief, appropriately diluted ceca mixture with saline was used to monitor ammonia concentration using an ammonia assay kit (Product code AA0100, Sigma, St. Louis, MO, USA). For viscosity, the intestinal contents between Meckel's diverticulum and the ileocecal junction were centrifuged at $9,000 \mathrm{rpm}$ for $10 \mathrm{~min}$ at $4^{\circ} \mathrm{C}$. The supernatant was used to measure viscosity using viscometer (LVDL-II+P CP, Brookfield, IL, USA) which was operated at $10 \mathrm{rpm}$ speed and viscosity value was recorded after $30 \mathrm{~s}$.

\section{Statistical analysis}

Replicate was considered as an experimental unit. All data were analyzed by analysis of variance using the General Linear Model procedure of SAS program (SAS, 2002). Differences between means were analyzed using Duncan's multiple range test. A statistical significance was preset at $\mathrm{p}<0.05$ unless otherwise stated.

\section{RESULTS}

\section{Feed intake and laying performance}

The effects of multiple enzyme preparation on feed intake and laying performance are presented in Table 2. No significant differences in feed intake, egg production and egg weight were observed between dietary treatments. Egg mass tended to be lower in $\mathrm{rE}$ or $\mathrm{rEP}$ groups compared with the control-diet fed chickens. The rE-, but not rEP-induced decrease in egg mass significantly relieved $(p<0.05)$ by supplementation of multiple enzyme preparation (e.g., rE-

Table 2. Effects of multiple enzyme preparation on feed intake and laying performance in laying hens

\begin{tabular}{lcccccc}
\hline Parameters & Control $^{1}$ & rE & rE-Natu500 & rEP & rEP-Natu500 & Pooled SEM \\
\hline Feed intake (g/d/bird) & 128.7 & 128.0 & 122.1 & 126.8 & 122.4 & 0.997 \\
Egg production (\%) & 91.8 & 90.4 & 92.8 & 90.6 & 91.4 & 0.327 \\
Egg weight (g/egg) & 68.5 & 67.8 & 68.3 & 68.0 & 68.2 & 0.100 \\
Egg mass (g/d/bird) & $62.9^{\text {ab }}$ & $61.3^{\mathrm{b}}$ & $63.5^{\mathrm{a}}$ & $61.6^{\mathrm{b}}$ & $62.4^{\text {ab }}$ & 0.237 \\
\hline
\end{tabular}

SEM, standard error of the mean.

${ }^{1}$ Control, corn-soybean meal based diet; rE, diet with the reduced level of energy and protein; rE-Natu500, rE+0.05\% Natuzyme; rEP, diet with the reduced level of energy, protein and available phosphorus; $r E P+0.05 \%$ Natuzyme.

${ }^{\mathrm{a}-\mathrm{b}}$ Means within a row with no common letter are significantly different $(\mathrm{p}<0.05)$. 
Table 3. Effects of multiple enzyme preparation on egg color, Haugh unit and eggshell qualities in laying hens

\begin{tabular}{lcccccc}
\hline Parameters & Control $^{1}$ & rE & rE-Natu500 & rEP & rEP-Natu500 & Pooled SEM \\
\hline Eggshell color & 25.0 & 26.0 & 25.4 & 25.0 & 26.0 & 0.198 \\
Yolk color, R.C.F & 7.40 & 7.31 & 7.41 & 7.29 & 7.39 & 0.030 \\
Haugh unit & 93.7 & 93.5 & 93.5 & 92.9 & 93.4 & 0.314 \\
Eggshell strength $\left(\mathrm{kg} / \mathrm{cm}^{2}\right)$ & $3.30^{\mathrm{b}}$ & $3.24^{\mathrm{b}}$ & $3.99^{\mathrm{a}}$ & $3.06^{\mathrm{b}}$ & $3.43^{\mathrm{ab}}$ & 0.031 \\
Eggshell thickness $(\mathrm{mm} / 100)$ & $36.5^{\mathrm{ab}}$ & $36.0^{\mathrm{bc}}$ & $37.1^{\mathrm{a}}$ & $35.4^{\mathrm{c}}$ & $36.6^{\mathrm{ab}}$ & 0.126 \\
\hline
\end{tabular}

SEM, standard error of the mean; RCF, the Roche color fan.

${ }^{1}$ Control, corn-soybean meal based diet; rE, diet with the reduced level of energy and protein; rE-Natu500, rE+0.05\% Natuzyme; rEP, diet with the reduced level of energy, protein and available phosphorus; rEP-Natu500, rEP+0.05\% Natuzyme.

${ }^{\mathrm{a}-\mathrm{c}}$ Means within a row with no common letter are significantly different $(\mathrm{p}<0.05)$.

Natu500) in layers' diet.

\section{Egg qualities}

Eggshell color, yolk color or Haugh unit were not affected by any of dietary treatments (Table 3). Eggshell strength in chickens fed on $\mathrm{rE}$ or $\mathrm{rEP}$ diet did not differ compared with that in the control-diet fed chickens. However, rE-Natu500-fed chickens had significantly higher $(p<0.05)$ eggshell strength compared with the rE-fed chickens. Eggshell thickness was significantly lower $(\mathrm{p}<0.05)$ in rEP-diet fed compared with the control-diet fed counterparts. Addition of multiple enzyme preparation into the $\mathrm{rE}$ or $\mathrm{rEP}$ diet significantly increased $(\mathrm{p}<0.05)$ eggshell strength.

\section{Blood profiles and relative organ weights}

Both GOP and GPT are considered as the indicators of liver functionality. Together with blood cholesterol levels, both GOT and GPT levels were not affected by any of the treatments (Table 4). Liver and spleen which expressed relative to body weight were not affected. It may well be likely that non-significant difference between dietary treatments indicates the superior performance of all birds with high efficiency irrespective to the presence or absence of the enzyme.

\section{Cecal microbial flora and ammonia concentration and intestinal viscosity}

Cecal microflora, i.e., total microbes, lactic acid bacteria or Coliforms were not affected by dietary treatments (Table 5). Cecal ammonia concentration and intestinal chyme viscosity in laying hens fed on $\mathrm{rE}$ or $\mathrm{rEP}$ diets were not different compared with those in the control-diet fed chickens. However, addition of multiple enzyme preparation into the $\mathrm{rE}$, but not $\mathrm{rEP}$ diet significantly lowered the ammonia concentration in cecal contents and intestinal chyme viscosity.

Table 4. Effects of multiple enzyme preparation on the blood profiles and relative weights of organs in laying hens

\begin{tabular}{lcccccc}
\hline Parameters & Control $^{1}$ & rE & rE-Natu500 & rEP & rEP-Natu500 & Pooled SEM \\
\hline TOTAL-C $(\mathrm{mg} / 100 \mathrm{~mL})$ & 121.4 & 128.1 & 119.7 & 126.3 & 125.6 & 2.445 \\
GOT $(\mathrm{U} / 100 \mathrm{~mL})$ & 100.5 & 105.9 & 105.3 & 106.5 & 100.7 & 1.793 \\
GPT $(\mathrm{U} / 100 \mathrm{~mL})$ & 7.23 & 7.14 & 7.37 & 7.45 & 7.82 & 0.260 \\
Liver $(\mathrm{g} / 100 \mathrm{~g} \mathrm{BW})$ & 1.81 & 1.70 & 1.71 & 1.80 & 1.78 & 0.029 \\
Spleen $(\mathrm{g} / 100 \mathrm{~g} \mathrm{BW})$ & 0.09 & 0.09 & 0.09 & 0.10 & 0.10 & 0.004 \\
\hline
\end{tabular}

SEM, standard error of the mean; TOTAL-C, total cholesterol; GOT, glutamic-oxaloacetic transaminase; GPT, glutamic-pyruvic transaminase.

${ }^{1}$ Control, corn-soybean meal based diet; rE, diet with the reduced level of energy and protein; rE-Natu500, rE+0.05\% Natuzyme; rEP, diet with the reduced level of energy, protein and available phosphorus; rEP-Natu500, rEP+0.05\% Natuzyme;

Table 5. Effects of multiple enzyme preparation on the profiles of cecal microflora and the ammonia concentrations and viscosities of intestinal content in laying hens

\begin{tabular}{lcccccc}
\hline Parameters & Control $^{1}$ & rE & rE-Natu500 & rEP & rEP-Natu500 & Pooled SEM \\
\hline Total microbes $\left(\log _{10} \mathrm{cfu} / \mathrm{g}\right)$ & 5.99 & 5.89 & 5.20 & 5.38 & 5.28 & 0.103 \\
Lactic acid bacteria $\left(\log _{10} \mathrm{cfu} / \mathrm{g}\right)$ & 7.12 & 7.19 & 6.99 & 7.08 & 6.85 & 0.066 \\
Coli forms $\left(\log _{10} \mathrm{cfu} / \mathrm{g}\right)$ & 5.26 & 5.52 & 5.24 & 5.35 & 4.88 & 0.129 \\
Ammonia concentration $(\mathrm{mg} / \mathrm{mL})$ & $2.19^{\mathrm{a}}$ & $2.15^{\mathrm{a}}$ & $1.67^{\mathrm{b}}$ & $2.01^{\mathrm{ab}}$ & $1.72^{\mathrm{b}}$ & 0.059 \\
Viscosity (mPas) & $5.35^{\mathrm{ab}}$ & $5.52^{\mathrm{a}}$ & $4.77^{\mathrm{c}}$ & $5.36^{\mathrm{ab}}$ & $4.89^{\mathrm{bc}}$ & 0.078 \\
\hline
\end{tabular}

SEM, standard error of the mean.

${ }^{1}$ Control, corn-soybean meal based diet; rE, diet with the reduced level of energy and protein; rE-Natu500, rE+0.05\% Natuzyme; rEP, diet with the reduced level of energy, protein and available phosphorus; rEP-Natu500, rEP+0.05\% Natuzyme.

${ }^{\mathrm{a}-\mathrm{c}}$ Means within a row with no common letter are significantly different $(\mathrm{p}<0.05)$. 


\section{DISCUSSION}

The current study evaluated the effect of multiple enzyme preparation (Natuzyme) on laying performance, egg qualities, organ weights, blood parameters, cecal microflora and viscosity in 43-wk-old laying hens. In this sense, the present experiment is straightforward and designed to address the efficacy of the commercial product which does not need the hypothesis to be tested. Nonetheless, it should be stressed that the current experiment had sufficient statistical power to detect any effects by the multiple enzyme preparation on the measured parameters in laying hens. Thus, we can say with confidence that the results obtained in this study will be considered of use with practical relevance to the poultry industry. The current experiment performed well and the overall laying performance maintained superior in all treated groups based on the guideline set by the breeder. Addition of the multiple enzyme preparation into the $\mathrm{rE}$ diet, but not rEP diet significantly increased egg mass and eggshell strength and thickness while it decreased cecal ammonia concentration and intestinal chyme viscosity in laying hens. Thus, the present study is in line with previous studies (Annison and Choct, 1991; Cowieson and Adeola, 2005; Adeola and Cowieson, 2011; Ravindran, 2013) that single enzyme or multiple enzyme preparation effectively lowered the anti-nutritional factors present in the diet, leading to improved performance in laying hens. It has been well reported that the multiple enzyme preparations possessed the multiple biological features such as increased egg mass, and eggshell strength and thickness, and decreased ammonia concentration and chyme viscosity in poultry (Bedford and Wyatt, 1998; Lazaro et al., 2003; Lim et al., 2003; Liu et al., 2007; Jang et al., 2008), of which effects are also observed in this study. It is however pointed out that there was no significant effect of adding the multiple enzyme preparation into the rEP diet which had slightly low energy, crude protein, and available phosphorus levels compared to the control diet. At this stage, clear explanation(s) on this perplexed observation is not readily available which needs to be addressed.

In conclusion, the present study clearly revealed that adding the multiple enzyme preparation into the laying hens' diets improved laying performance and intestinal physiological parameters such as ammonia concentration and chyme viscosity. Further studies are needed to address the kinetic relationship between varying enzyme and phytic acid concentrations, and to test whether the multiple enzyme preparation can help maintain laying performance with high efficiency with later ages.

\section{ACKNOWLEDGMENTS}

This paper was supported by KonKuk University in
2014. We thank In-Sook An in the Poultry Nutrition Laboratory, Department of Animal Science and Technology, College of Animal Bioscience and Technology, KonKuk University for the technical assistance.

\section{CONFLICT OF INTEREST}

We certify that there is no conflict of interest with any financial organization regarding the material discussed in the manuscript.

\section{REFERENCES}

Adeola, O. and A. J. Cowieson. 2011. Board-invited review: Opportunities and challenges in using exogenous enzymes to improve nonruminant animal production. J. Anim. Sci. 89:3189-3218.

Annison, G. and M. Choct. 1991. Anti-nutritive activities of cereal non-starch polysaccharides in broiler diets and strategies minimizing their effects. World's Poult. Sci. J. 47:232-242.

Bedford, M. R. and H. Schulze. 1998. Exogenous enzymes in pigs and poultry. Nutr. Res. Rev. 11:91-114.

Bedford, M. R. and C. Wyatt. 1998. Using feed enzymes to maximize nutrient utilization in corn-soy or sorghum-soy based layer diets. Zootecnica Int. 9:32-35.

Cowieson, A. J. and O. Adeola. 2005. Carbohydrase, protease, and phytase have an additive beneficial effect in nutritionally marginal diets for broiler chicks. Poult. Sci. 84:1860-1867.

Han, S. W., K. W. Lee, B. D. Lee, and C. G. Sung. 1999. Effect of feeding Aspergillus oryzae culture on fecal microflora, egg qualities, and nutrient metabolizabilities in laying hens. Asian Australas. J. Anim. Sci. 12:417-421.

Jang, H. D., Y. Hyun, H. S. Kim, I. W. Hwang, J. S. Yoo, H. J. Kim, S. O. Shin, Y. Hwang, T. X. Zhou, Y. J. Chen, J. H. Cho, and I. H. Kim. 2008. Effect of dietary microbial phytase on laying performance, egg quality, phosphorus utilization and nutrient metabolizability in laying hens. Korean J. Poult. Sci. 35:115121.

Lazaro, R., M. Garcia, P. Medel, and G. G. Mateos. 2003. Influence of enzyme on performance and digestive parameters of broiler fed rye-based diets. Poult. Sci. 82:132-140.

Lee, S. Y., J. S. Kim, J. M. Kim, B. K. An, and C. W. Kang. 2010. Effects of multiple enzyme of NSP enzymes and phytase (ROVABIO ${ }^{\circledR}$ Max) supplemented to corn-wheat-soybean meal based diets on growth performance and intestinal viscosity in broiler chicks. Asian Australas. J. Anim. Sci. 23:1198-1204.

Lee, K.W., H. S. Lillehoj, S. I. Jang, S. H. Lee, D. A. Bautista, and G. R. Siragusa. 2013. Effect of Bacillus subtilis-based directfed microbials on immune status in broiler chickens raised on fresh or used litter. Asian Australas. J. Anim. Sci. 26:15921597.

Lee, K. W., G. X. Li, H. S. Lillehoj, S. H. Lee, S. I. Jang, U. S. Babu, E. P. Lillehoj, A. P. Neumann, and G. R. Siragusa. 2011. Bacillus subtilis-based direct-fed microbials augment macrophage function in broiler chickens. Res. Vet. Sci. 91:e87e91.

Lillehoj, H. S. and K. W. Lee. 2012. Immune modulation of innate 
immunity as alternatives-to-antibiotics strategies to mitigate the use of drugs in poultry production. Poult. Sci. 91:12861291.

Lim, H. S., H. Namkung, and I. K. Paik. 2003. Effects of phytase supplementation on the performance, egg quality, and phosphorus excretion of laying hens fed different levels of dietary calcium and nonphytate phosphorus. Poult. Sci. 82:9299.
Liu, J. R., S. F. Lai, and B. Yu. 2007. Evaluation of an intestinal lactobacillus reuteri strain expressing rumen fungal xylanase as a probiotic for broiler chickens fed on a wheat-based diet. Br. Poult. Sci. 48:507-514.

National Research Council. 1994. Nutrient requirements of poultry. 9th ed. National Academy Press. Washington DC, USA.

Ravindran, V. 2013. Feed enzymes: The science, practice, and metabolic realities. J. Appl. Poult. Res. 22:628-636.

SAS. 2002. SAS user's guide. Statistics, Version 8. e., SAS Institute. Inc. Cary, NC, USA. 